\title{
Flaxseed- Bioactive compounds and health significance
}

\author{
Prof. Sunita Mishra*, PoojaVerma \\ Department of Human Development and Family Studies, School for Home Sciences, Babasaheb Bhimrao \\ Ambedkar University (Central University),Vidya Vihar, Raebareli Road,Lucknow 226025
}

\begin{abstract}
Flaxseed is extensively consumed in three ways: whole seed, powder and flaxseed oil. In the last decade, flaxseed has garnered attention due to its reported health benefits. Studies have shown that the benefits of flaxseed are believed to be due three important components found in flaxseeds, $\alpha$-linolenic acid (ALA), lignans, and fiber. The presence of these bioactive compounds helps in the prevention of cardiovascular diseases, diabetes, memory loss, and constipation. The phenolic compounds of flaxseed help in reduction of the fasting plasma glucose levels. Flaxseed contains biologically active estrogenic compounds called phytoestrogens which helps in decreasing cell proliferation and prevents cancer. Higher levels of flaxseed are associated with prevention of memory loss and constipation. Flaxseed also contains several non-nutritional compounds such as cyanogenic glycosides, cadmium, trypsin inhibitors and phytic acid that negatively influence health and well-being.
\end{abstract}

Keywords:Flaxseed, $\alpha$-linolenic acid (ALA), lignans, fiber, cardiovascular diseases, diabetes, phytoestrogens

\section{Introduction}

Flaxseed or linseed (Linum usitatissimum L.) has been used as food and medicines in many countries. Flaxseed comes from the flax plant, which is an annual herb. It has been used in various forms such as flour, oil and seed. Flaxseed and flaxseed oil is considered as healthy due to presence of various bioactive compounds in it.

The seed is a healthy source of oil containing poly-unsaturated fatty acids, digestible proteins, and lignans. Major nutritional components of flaxseed include ALA rich oil, protein, minerals and a greater proportion of nonnutritional lignan-rich dietary fiber. On the dry weight basis, flaxseed contain $20 \%$ protein, $27 \%$ total dietary fiber $41 \%$ oil, $4 \%$ ash and $8 \%$ moisture. Albeit, flaxseed proteins are not complete in nature but the deficiency may be overcome effectively by enrichment with products containing amino acids that form complete proteins.[1]

Flours extracted from some other edible grains like oat, barley, flaxseed can provide an ample quantity of good quality protein and dietary fiber and contribute effectively in the reduction of chronic disorders like cardiovascular diseases, cancer and diabetes.[2]

\section{Bioactive Constituents in Flaxseed}

Alpha-linolenic acid (ALA), unsaturated fatty acids (linolenic acid, linoleic acid, oleic acid), soluble flaxseed fiber mucilage (d-Xylose, L-Galactose, LRhamnose, d-galacturonic acid), lignans (secoisolariciresinol diglycoside (SDG)), monoglycerides, triglycerides, free sterols, sterol esters, hydrocarbons (protein), balast, phenylpropane derivatives.[3]

Flaxseed also contains monounsaturated fatty acids (MUFAs), such as oleic acid. ALA and linoleic acid are both essential fatty acids (EFA), meaning they cannot be synthesized by the human body and must be derived from the diet. $[4,5,6]$

\section{Botanical classification of Flaxseed-}

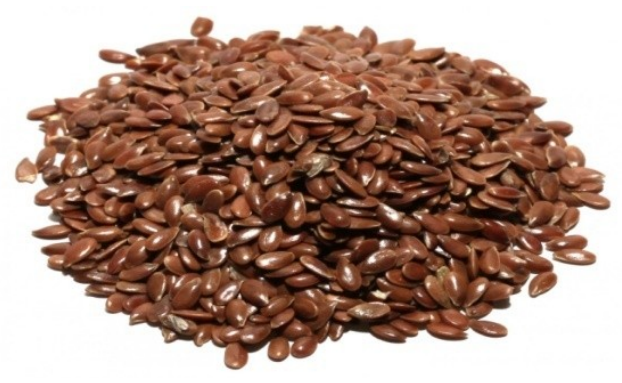


Common name: Flax

Latin name: Linum usitatissimum,

Synonyms: Linseed, Common Flax, Flax Weed, Lint Bells, and Toad Flax

Family: Linaceae

Habitat: The plant is native to the temperate regions of Europe and Asia.

Description: Flax is a small, herbaceous, annual plant, growing to 1, 2 meters tall. It has erect, smooth stem and glaucous green, linear leaves. Flowers are small, five-petalled, pale blue or bright red in color. Fruits are round, dry capsules filled with brown seeds.

Parts used: Seed

\section{Role of flaxseed in prevention of diseases}

Various clinical and epidemiological studies have shown that the presence of bioactive constituents of flaxseeds have the potential of reducing the various diseases such as cardiovascular ailments, strokes, diabetes, cancer etc.

\section{Prevention of cardiovascular diseases}

An emerging class of phytoestrogens i.e. ALA and dietary lignans have been reported by Mandasescu et al. [7] to be excessively available in flaxseed and believed to carry lipid-lowering and antioxidant properties that positively alter cardiovascular risk. Being a good source of ALA, flaxseed increases its levels in serum if consumed with regular diet. In another study by Bloedon et al. [8] on flaxseed demonstrated modest low density lipoprotein cholesterol (LDL-C) reducing effect on lipoproteins and improved insulin sensitivity in hyperlipidemic adults. The study conferred a reduction in LDL-C by $\sim 14 \%$ levels after continuous consumption for a period of 5 weeks as compared to wheat. The aforementioned findings are well supported by the work of Dodin et al. [9] that ingestion of yellow flaxseed powder $\sim 40 \mathrm{~g}$ reduces blood serum HDL cholesterol levels of menopausal women to a significant extent.

Eicosanoides derived from omega-3-fatty acids, present in flaxseed primarily improves heart function by reducing blood cholesterol. A proportionate effect on blood cholesterol concentration and low-density lipoprotein fraction has been linked with higher concentrations of flaxseeds in the diets indicating greater reduction in LDL protein, serum and liver cholesterol $[10,11]$. Various studies report significant beneficial effect of flaxseed on the heart function suggesting a daily consumption of $40 \mathrm{~g}$ of whole yellow omega flaxseed ground into powder and supplemented in baked products modulates several CVD risk markers. $[9,7,8]$

\section{Prevention of diabetes}

Diabetes is a chronic disease caused by deficiency in insulin production or by ineffectiveness of the insulin produced, resulting in increased blood glucose levels which cause damage to body systems, in particular the blood vessels and nerves.[12]

Hypercholesterolaemic postmenopausal women showed reduced glucose and insulin levels after eating flaxseed. [13] In another group of hypercholesterolaemic subjects, the phenolic complex reduced the fasting plasma glucose levels. [14] In a study by Pan et al. (2007) [15], hypercholesterolaemic postmenopausal women diagnosed with type II diabetes showed small improvements in long-term glycaemic control but no effect on fasting glucose or insulin sensitivity after eating low amounts of the phenolic complex for eight weeks. SDG has been demonstrated to prevent or delay the development of type I and II diabetes in diabetes-prone rats, probably by decreasing oxidative stress in body tissues. [16]

In a case series including 15 obese patients, Nestel et al. [17] reported that a four-week diet high in alpha-linolenic acid (ALA) (20g from margarine products based on flax oil) diminished insulin sensitivity.[18]In men with type 2 diabetes, ingestion of omega-3 fatty acids (not specific to flax) showed increases in fasting glucose levels and a $22 \%$ increase in mixed meal glucose levels.[19]

\section{Prevention in cancer}

A broad study have been reported by Power and Thompson (2011) critically focusing reduction in the process of cancer progression in relation to the consumption of flaxseed and its antioxidant, estrogenic, and antiestrogenic effects that influence the prostate cellular proliferation.[20] Phytoestrogens are biologically active estrogenic compounds found in flaxseed that influence protein synthesis, cell proliferation, hormone metabolism, angiogenesis and intracellular enzymes.[21] Mammalian metabolites of flaxseed lignans i.e. enterodiol and enterolactone can serve as a protective approach to cope with pre-cancer cellular alterations. Like phytoestrogens, flaxseed lignans metabolize estrogens and are supposed to serve in prostate and breast cancer prevention strategies as an adjuvant in hormone replacement therapy. [22, 23, 24] Omega-6 and omega-3 fatty acids sources i.e. fats with natural or enriched higher concentration from corn oil and flaxseed oil, respectively, play a significant role in inhibiting development of chemically induced tumors in laboratory animals thus 
reducing chances of colon cancer initiation.[22] Flaxseed cotyledons based diet feed to tumor induced mice $(82 \mathrm{~g} / \mathrm{kg})$ for a period of 8 weeks significantly lowers the cell proliferation process and reduces tumor growth area. [25] Dietary combination of flaxseed oil $(8 \%)$ with primary anticancer drugs can significantly reduce breast tumor development $\sim 89 \%$ as compare to primary drug treatment alone for a period of 4 weeks. [26]

Although not extensively evaluated, flaxseed has been shown to inhibit colon and skin cancers in cell cultures and in animal studies.[27, 28] In other study it was reported that a $10 \mathrm{mg} / \mathrm{kg}$ dose of enterolactone, by subcutaneous injection 3 times per week, reduced the expression of colon 201 human colon cancer cells in athymic mice. Using various testing protocols, it is concluded that the tumor suppression was due to apoptosis and decreased cell proliferation. In general, flaxseed may be a valuable tool in the fight against various cancers. Further research is needed in clinical settings to support the role of flaxseed in cancer prevention in human populations.[29]

\section{Prevention from memory loss}

Loss in spatial memory is very much associated with accumulation of lipid peroxide in the hippocampus. Higher levels of flaxseed nutritional as well as non-nutritional components like antioxidants in the form N-3 fatty acids most often referred as $\omega$-3 fatty acids i.e. ALA, docosahexaenoic acid (DHA) and dietary fibers i.e. lignans, in addition to reduction of body mass reduces levels of lipid peroxide in the hippocampus. Studies on flax feed dam suggest that improvement in hippocampus ALA and DHA concentration results in reduction of spatial memory inhibitors thus increases learning ability of flaxseed feed dams [30]

\section{Prevention from constipation}

The recommended amount of daily dietary fiber of $>25 \mathrm{~g}$ is, according to many studies, useful in the treatment of constipation. Ground flaxseed consists of $40 \%$ of dietary fiber, $2 / 3$ of which is insoluble (cellulose, hemicellulose and lignin) and 1/3 is soluble fiber. Insoluble fiber binds water and thus increases the bulk in colon. Soluble fiber from flaxseed mucilage has similar effects than guar gum or ispaghula, e.g. delay in gastric emptying, improvement in glycemic control and alleviation of constipation. The mean dietary fiber intake in western countries is approximately $20 \mathrm{~g} / \mathrm{day}$. Flaxseed supplement of $10-20 \mathrm{~g} / \mathrm{d}$ would increase the intake to the recommended level of 25-30 g/day. However, the use of flaxseed has to be long term as the full effects are only observed after two months. Roughly ground flaxseed seems to have better water-binding capacity than the finely ground flaxseed meal.

\section{Presence of antinutrients in flaxseed}

Flaxseed has several compounds that may negatively influence health and well-being. In some cases, the negative impact might simply be an assumption based on literature reports of similar compounds from other foods. The 2 components that have been questioned most frequently are the cyanogenic glycosides, cadmium, phytic acid and trypsin inhibitor.

\section{Cyanogenic glycosides}

Cyanogenic glycosides are not exclusive to flaxseed. These compounds can be found in a number of plants including brassica vegetables and especially cassava. Many of the health concerns regarding cyanogenic glycosides stem from studies showing that cassava was toxic to animals and humans. [31] At the recommend daily intake of about 1 to 2 tablespoons, approximately 5 to $10 \mathrm{mg}$ of hydrogen cyanide is released from flaxseed, which is well below the estimated acute toxic dose for an adult of 50 to $60 \mathrm{mg}$ inorganic cyanide and below the 30 to $100 \mathrm{mg} / \mathrm{d}$ humans can routinely detoxify.[32]

\section{Cadmium}

Flaxseeds accumulate cadmium from soil, especially from artificially fertilized soil. The cadmium content of a flaxseed product investigated was analyzed to be $0.84 \mathrm{mg} / \mathrm{kg}$.[33] Cadmium accumulates in the liver and kidneys, where the proteins called metallothioneins bind it. The amount of these proteins increases after cadmium exposure. In the kidney, the metallothioneins seem to protect the tissue as long as the tissue concentration is below $200 \mu \mathrm{g}$. Above this concentration damage to the kidney tubuli occurs resulting in proteinuria. Cadmium has a half-life of 10-40 years and is eliminated probably via the kidneys or bile. The daily amount of cadmium, which can cause accumulation in body, is considered to be 200-300 $\mu \mathrm{g}$. [34]

\section{Trypsin inhibitors and phytic acid}

Trypsin inhibitor and phytic acid are other antinutrients contained in flaxseed. But compared to soyabean and canola seeds, activity of them are low.[35] In a study it was reported that the laboratory-prepared flaxseed meals containing 42-51 units of TIA (Trypsin inhibitor activity), [36] which was slightly higher than 10-30 units [37] and commercially obtained flaxseed meal (14-37 units). The antipyridoxine factor linatine was 
also identified.[38] Although linatine is a problem in chicks, flaxseed has not been associated with a vitamin B6 deficiency in humans. In fact, no effect on serum pyridoxine levels in subjects consuming 45 grams of flaxseed per day over $5 \mathrm{wk}$ has been observed.[39]

\section{Conclusion}

Flaxseeds (Linseed) due to its health beneficial compounds have generated interest. Various studies have been done on the nutritional aspects and medical applications but more studies are needed to understand the curative properties of flaxseed. The components present in flaxseed attract the food technologists and nutritionists to explore its activities in health sector. Today a major portion of world is suffering from disorders like cardiovascular diseases, diabetes, hypertension, neurological disorders hence there is a need to cure the people by adopting natural strategy. Flaxseed is one of the emerging foods which have the potential of curing these disorders. The incorporation of medicinal plants towards the development of nutritional food products fights the disorders which are associated with unhealthy life style and secondly, they are safer as they are natural foods, they don't cause any side effect.

\section{References}

[1]. Madhusudhan B (2009). Potential benefits of flaxseed in health and disease-A perspective. Agro Conspec Sci., 74: 67-72.

[2]. Pourafshar S, Rosentrater KA and Krishnan P (2010). A review of alternatives to wheat flour. Am. Soc. Agric.Biol. Eng. Annu. Int. Meet., 2: 1527-1540.

[3]. Abarzua, S., Szewczyk, M., Gailus, S., Richter, D. U., Ruth, W., Briese, V., and Piechulla, B. Effects of phytoestrogen extracts from Linum usitatissimum on the Jeg3

[4]. Dyerberg, J. Linolenate-derived polyunsaturated fatty acids and prevention of atherosclerosis. Nutr Rev 1986; 44(4):125-134

[5]. Siguel, E. N. Essential and trans fatty acid metabolism in health and disease. Compr Ther 1994;20(9):500-510.

[6]. Stoll, A. L., Locke, C. A., Marangell, L. B., and Severus, W. E. Omega-3 fatty acids and bipolar disorder: a review. Prostaglandins Leukot Essent Fatty Acids 1999;60(5-6):329-337.

[7]. Mandasescu S, Mocanu V, Dascaliţa AM, Haliga R, Nestian I, Stitt PA and Luca V (2005). Flaxseed supplementation in hyperlipidemic patients. Rev. Med. Chir. Soc. Med. Nat. Iasi., 109: 502-506.

[8]. Bloedon LT, Balikai S, Chittams J, Cunnane SC, Berlin JA, Rader DJ and Szapary PO (2008). Flaxseed and cardiovascular risk factors: results from a double blind, randomized, controlled clinical trial. J. Am. Coll. Nutr.,27: 65-74

[9]. Dodin S, Lemay A, Jacques H, Legare F, Forest JC and Masse B (2005). The effects of flaxseed dietary supplement on lipid profile, bone-mineral density, and symptoms in menopausal women: A randomized double blind, wheat germ placebo-controlled trial. $J$. Clin. Endocrinol. Metab., 90: 1390-1397.

[10]. Gambus H, Mikulec A, Gambus F and Pisulewski P (2004). Perespectives of linseed utilization in baking. Pol. J. Food. Nutr. Sci., 13: $21-27$.

[11]. Cintra DEC, Costa AGV, Peluzio MCG, Matta SLP, Silva MTC and Costa NMB (2006). Lipid profile of rats fed high-fat diets based on flaxseed, peanut, trout, or chicken skin. Nutr., 22: 197-205.

[12]. WHO, 2009 c. (online) http://www.who.int/diabetesactiononline/diabetes/en/ (2009-08-15)

[13]. Lemay, A., Dodin, S., Kadri, N., Jacques, H. \& Forest, J-C. 2002. Flaxseed dietary supplement versus hormone replacement therapy in hypercholesterolemic menopausal women. The American College of Obstetricans and Gynecologists, 100(3):495-504.

[14]. Zhang, W., Wang, X., Liu, Y., Flinkinger, B., Empie, M.W. \& Sun, S.Z. 2008. Dietary flaxseed lignan extract lowers plasma cholesterol and glucose concentrations in hypercholesterolaemic subjects. British Journal of Nutrition, 99:1301-1309.

[15]. Pan, A., Sun, J., Chen, Y., Ye, X., Li, H., Wang, Y., Gu, W., Zhang, X., Chen, X., Demark-Wahnefried, W., Liu, Y. \& Lin X. 2007. Effects of a flaxseed-derived lignin supplement in type 2 diabetic patients: A randomized, double blind, cross-over trial. PLoS ONE, 2(11): e1148.

[16]. Prasad, K. 2000. Oxidative stress as a mechanism of diabetes in diabetic BB prone rats: Effect of secoisolariciresinol digluc oside (SDG). Molecular and Cellular Biochemistry, 209:89-96.

[17]. Nestel, P. J., Pomeroy, S. E., Sasahara, T., Yamashita, T., Liang, Y. L., Dart, A. M., Jennings, G. L., Abbey, M., and Cameron, J. D. Arterial compliance in obese subjects is improved with dietary plant n- 3 fatty acid from flaxseed oil despite increased LDL oxidizability. Arterioscler Thromb Vasc Biol 1997; 17(6):1163-1170.

[18]. Glauber, H., Wallace, P., Griver, K., and Brechtel, G. Adverse metabolic effect of omega-3 fatty acids in non-insulin- dependent diabetes mellitus. Ann Intern Med 1988; 108(5):663-668.

[19]. Power KA and Thompson LU (2011). The potential role of seeds and seeds bioactives on the prevention and treatment of breast and prostate cancer. In: Muntanen M, Pajari AM (editors). Vegetables, whole grains, and their derivatives in cancer prevention. Diet and Cancer, 2: pp. 172-801.

[20]. Branca F and Lorenzetti S (2005). Health effects of phytoestrogens. Forum Nutr., 57: 100-111.

[21]. Thompson LU, Chen JM, Li T, Strasser-Weippl K and Goss PE (2005). Dietary flaxseed alters biological markers in postmenopausal breast cancer. Clin. Cancer Res., 11: 3828-3835.

[22]. Knust U, Spiegelhalder B, Strowitzki T and Owen RW (2006). Contribution of linseed to urine and serum enterolignan levels in German females: A randomized controlled intervention trial. Food Chem. Toxicol., 44: 1057-1064.

[23]. Adolphe JL, Whiting SJ, Juurlink BHJ, Thorpe LU and Alcorn J (2010). Health effects with consumption of flax lignan secoisolariciresinol diglucoside. Br. J. Nutr., 103: 929-938.

[24]. Bhatia E, Doddivenaka C, Zhang X, Bommareddy A, Krishnan P, Matthees DP and Dwivedi C (2011). Chemopreventive effects of dietary canola oil on colon cancer development. Nutr. Cancer, 63: 242-247.

[25]. Chen J, Saggar JK, Corey P and Thompson LU (2011). Flaxseed cotyledon fraction reduces tumour growth and sensitises tamoxifen treatment of human breast cancer xenograft (MCF-7) in athymic mice. Br. J. Nutr., 105: 339-347.

[26]. Mason JK, Chen J and Thompson LU (2010). Flaxseed oil-trastuzumab interaction in breast cancer. Food Chem. Toxicol., 48: 22232226.

[27]. Thompson LU. 2003. Flaxseed, lignans, and cancer. In: Thompson LU, Cunnane SC, editors. Flaxseed in human nutrition. 2nd ed. Champaign, Ill.: AOCS Press. p 194-218.

[28]. Morris DM. 2003. Flax, a health and nutrition primer. Winnipeg, Manitoba, Canada: Flax Council of Canada. p 9-19. 
[29]. Danbara N, Yuri T, Tsujita-Kyutoku M, Tsukamoto R, Uehara N, Tsubura A. 2005. Enterolactone induces apoptosis and inhibits growth of colon 201 human colon cancer cells both in vitro and in vivo. Anticancer Res 25:2269-76.

[30]. Fernandes FS, de Souza AS, do Carmo MDT and Boaventura GT (2011). Maternal intake of flaxseedbased diet (Linum usitatissimum) on hippocampus fatty acid profile: Implications for growth, locomotor activity and spatial memory. Nutr., 10: 10401047. Fukumitsu S, Aida K, Shimizu H and Toyoda K (2010). Flaxseed lignan lowers blood cholesterol and decreases liver disease risk factors in moderately hypercholesterolemic men. Nutr. Res., 30: 441-446.

[31]. McMahon JM, White WLB, Sayre RT. 1995. Cyanogenesis in cassava (Manihot esculenta Crantz). J Exp Botany 46:731-41.

[32]. Roseling H. 1994. Measuring effects in humans of dietary cyanide exposure to sublethal cyanogens from Cassava in Africa. Acta Hort 375:271-83.

[33]. Tarpila, S., Tarpila, A., Gröhn, P., Silvennoinen, T., Lindberg,L. (2004) Efficacy of ground flaxseed on constipation in patients with irritable bowel syndrome. Current Topics in Nutraceutical Research, 2, 119-125.

[34]. Meberg, A., Sande, H., Foss, O.P., Stenwig, J.T. (1979) Smoking during pregnancy - effects on the fetus and on thiocyanate levels in mother and baby. Acta Paediatrica Scandinavica 68,547-552.

[35]. Hall, C. and Shultz, K. 2001. Phenolic antioxidant interactions. In Abstracts of the 92nd American Oil Chemists Society Annual Meeting and Expo. p. S88 Minneapolis, Minnesota: AOCS

[36]. Bhatty, R.S. 1993. Further compositional analyses of flax: Mucilage, trypsin inhibitors and hydrocyanic acid. Journal of American Oil Chemist Society 70 (9): 899-904.

[37]. Madusudhan, K.T. and Singh, N. 1983. Studies on linseed proteins. Journal of Agricultural and Food Chemistry 31 (5): $959-963$.

[38]. Klosterman HJ, Lamoureux GL, Parsons JL. 1967. Isolation, characterization, and synthesis of linatine. Avitamin B6 antagonist from flaxseed (Linum ustitatissimum). Biochemist 6:170-7.

[39]. Dieken HA. 1992. Use of flaxseed as a source of omega-3 fatty acids in human nutrition. In the 54th proceeding of Flax Inst. of United States. p 1-4. 